See discussions, stats, and author profiles for this publication at: https://www.researchgate.net/publication/288834558

\title{
The Australian Good Life: The Fraying of a Suburban Template
}

Article in Built Environment · December 2015

DOI: 10.2148/benv.41.4.504

1 author:

P Paul Burton

Griffith University

78 PUBLICATIONS 597 CITATIONS

SEE PROFILE

Some of the authors of this publication are also working on these related projects:

Project Major Sport Event Legacy Evaluation View project

Citizens Juries and health policy making View project 


\title{
The Australian Good Life:
}

\section{The Fraying of a Suburban Template}

\section{Paul Burton}

This paper is published in

\author{
'Suburban Spaces, Suburban Cultures' \\ Vol 41, No 4 of Built Environment \\ Guest Editors: Paul Burton and Jo Gill
}

Copyright of the published version remains with Alexandrine Press

cite as:

Burton, P. (2015) The Australian Good Life: The Fraying of a Suburban Template, Built Environment, vol 41, no 4, 504-518

Available to subscribers at:

http://www.ingentaconnect.com/content/alex/benv/2015/00000041/00000004/art00006 


\section{Introduction}

The urban historian Graeme Davison has described Australia as 'a mental suburb of England', a place in which for almost 150 years an idealised suburban existence has provided a template of the good life for most Australians. Towards the end of the last century this began to change, in the face of cultural, economic and political criticism but also, and perhaps more pertinently, in response to market adjustments by developers looking to create new markets for new housing products. While these criticisms have not gone unanswered and new but relatively conventional suburban developments continue to appear on the fringes of our major cities, the Australian suburban good life template is perhaps beginning to fray.

For places that are often portrayed in popular culture as somewhat bland and uninspiring, suburbs and suburban cultures can provoke passionate debate among urban scholars (Davison, 2013; Pini \& Previte, 2013; Stretton, 1971; Troy, 1996) and other commentators (Davies, 2012; King, 2013; Fox, 2014). As Paul Barker said recently of English suburbia,

Its vociferous enemies fail to see it as an essential ingredient of city life. Such critics are outnumbered many, many times by the millions for whom suburbia is a land of pleasantness, friendship and hope. (Barker, 2009: 10)

In his influential work on the country and the city Raymond Williams (1973) went beyond the simple debunking of stereotypical images of the places that frame suburbia and in this paper I too hope to consider how and why the stereotypes of suburban bliss or blandness persist in both scholarly and popular debates about housing and lifestyle in Australia. The importance of the suburban imaginary in contemporary urban policy debates in Australia cannot be overstated and there remains a high degree of polarisation between those who see Australian suburbia as the foundation of an unsustainable and consumptive lifestyle and those who claim the opposite, that it is in fact the best answer to the antipodean urban question: where and how should we live the good life? 
Contemporary urban policy debates must therefore engage with these suburban questions: should we be building more of the same or some other, probably more dense urban forms to accommodate the expected growth in the Australian population; should we be trying to substantially alter and retrofit the built form of our existing suburbs or are they as good as it gets; does the very notion of the suburb as a particular place that combines the best of town and country life retain any analytical power or conceptual clarity (Healy,1994)? To begin to answer these questions properly requires a more empirically grounded appreciation of the diversity of suburban forms and cultures, a more thoroughgoing historical perspective on their emergence and transformation and a better appreciation of the political economy of processes of suburban development.

The paper begins by critically reviewing the longevity of the English suburban template that was transplanted in Australia during the $19^{\text {th }}$ century and the factors that appear to be leading to its fraying. It then explores some of the manifestation of these changes in South East Queensland and especially in and around the Gold Coast, a place which has grown rapidly over the last half century to become Australia's sixth largest city and a place that for many embodies changing notions of an Australian suburban good life as well as its contemporary challenges. The paper concludes by reflecting on the likely future value of the suburban template of a good life in Australia and on the analytical purchase offered by the concept of suburbia.

\section{The British suburban template}

Toward the end of the $18^{\text {th }}$ century, as Britain looked toward the great southern land for new colonial opportunities to help, among other things, accommodate its burgeoning prison population (Morgan, 2012), new forms of urban development were emerging in London which were to profoundly alter the spatial organisation of cities. Fishman (1987) describes how before this period of colonial expansion English cities of the pre-industrial and pre-capitalist era reflected very clear distinctions between the inner and outer parts of towns and cities, which were built on the principle, 
...that the core was the only appropriate and honorific setting for the elite, and that the urban peripheries outside the walls were disreputable zones, shantytowns to which the poorest inhabitants and the most noisome manufacturers were relegated. (p23) (emphasis added)

He also notes how until the 1750s the suburbe on the urban fringe was defined by the Oxford English Dictionary as a place '..of inferior, debased, and especially licentious habits of life' and that in Shakespeare's time to call a man a suburbanite was a serious insult. To describe something as 'suburban' is probably still one of the more pointed and class-related ways in Britain to dismiss something or someone, and perhaps the label even has some derogatory purchase in 'classless' Australia (Winton, 2013). However, once the hard edges around urban settlements became less significant and as cities expanded beyond their fortified walls, so the possibility of a more sophisticated and complex gradient of settlement form and function became possible. Of course there had always been spatial distinctions within the city walls: between the palaces of kings and the homes of the common people; between places of worship and places of commerce and between public and private spaces, even if those distinctions were more blurred than they are now. But as cities grew beyond their walls so new types of space were created.

What then triggered and fuelled this transformation of the pre-modern notion of a disreputable suburban fringe into its modern form (Mechlenborg, 2007) as a place of 'pleasantness, friendship and hope'? Fishman (1987: 25) describes how English and North American processes of suburbanisation were 'improvised, not designed', with planners and architects playing only a modest role in these process. In fact, he argues it was the gradual emergence of new middle class or bourgeois family formations associated with the rise of industrial capitalism, more self-centred and keen to construct substantial physical boundaries around themselves that led to a growing desire for what was to become suburban detachment. These new and emerging middle class nuclear families began to assert themselves throughout $19^{\text {th }}$ century England and North America in various ways, including in their preference for living away from the man's place of work and for the home to become an emotional 
place where nuclear families lived their lives mainly in private as much as a place of economic production shared with a wider group of extended family members and workers.

Harvey (1989) has written extensively on the emergence of class-exclusive neighbourhoods as part of more general processes of capitalist urban development whereby the emergence of a new middle class in the USA and the UK in the early years of the $20^{\text {th }}$ century marked the increasing significance and reach of an ideology of 'possessive individualism' which helped drive a desire to live in middle class urban enclaves. However, he is also at pains to point out that this process is not simply an expression of individual consumer desire, but an unavoidable element of the capitalist mode of production and the social relations it embodies,

...it creates a structure that individuals can potentially choose from but that they cannot influence the production of. (Harvey, 1989: 121)

This tension between individual agency and structural imperative is not, of course, new (Giddens, 1984) but is especially pertinent in tracing the growth of suburbs and understanding processes of suburbanisation. The lack of planning - in the sense of conscious, concerted and broad scale intervention by bodies with some degree of authority - in $18^{\text {th }}$ century English suburban growth is notable but perhaps not surprising. At that time the design professions did not extend much beyond architecture and landscape design, and town planning would not emerge as a regulatory profession for at least one hundred years. Nevertheless, there has always been a narrative of suburbanisation as a spontaneous and 'natural' expression of residential preferences rather than the product of strategic planning. Barker's (2009) celebration of the 'freedoms of suburbia' is as much a critique of British town planning as he argues that apart from the initial subdivision of land for housebuilding, the English suburb has typically reflected an apparent freedom to build virtually what you wanted on your block of land, to embellish or modify the suburban house that you bought from someone else and to defend it from outside interference. And of course this attitude has been an integral part of the Australian suburban narrative, best exemplified in Rob Sitch's 1997 film The Castle. 
This is not of course to say that the detailed planning and design of residential estates and the regulation of processes of subdivision is not now commonplace and essential to the production of suburban environments, but rather that there are few examples of national, regional or local government policies in Australia that explicitly favour suburbanisation or a suburban aesthetic. Rather, it is often the by-product of something else, an almost taken for granted assumption that low density, peripheral expansion is the best way for our towns and cities to accommodate a growing population. In the USA, Lang \& LeFurgy (2007) describe how this process leads to the creation of 'accidental cities' or 'boomburbs' in which there are some of the trappings of urban life but no clearly recognised central business district or even cultural centre, while Sieverts (2003, x) details similar processes at work in Europe in the creation of Zwischenstadt in which '..the old contrast between city and country has dissolved into a city-country continuum' or a constellation of 'cities without cities'..

In England the prospect of living in relatively new small settlements on the urban fringe proved economically attractive to a new set of house builders able to transform fairly cheap agricultural land on the edge of cities into profitable suburban subdivisions. During this period in $19^{\text {th }}$ century England the new middle class had not yet acquired a taste for colonising and gentrifying existing rural villages, which were still seen mainly as places of poverty, while in Australia there was no equivalent pattern of preexisting villages to serve as the foundation for urban colonisation and gentrification. In England the explicit promotion of new settlements that combined the best of town and country living while preventing a sprawling blandness became the rallying cry of the Garden City movement, led by Ebenezer Howard and put into practice initially by Raymond Unwin and Barry Parker in Letchworth (Hall, 1974), while in Australia this took hold through the advocacy of planning pioneers such as Charles Reade and John Sulman (Freestone, 2010) and became manifest in residential developments at Daceyville in Sydney and Colonel Light Gardens in Adelaide. There is a clear lineage in Australia from these early suburban developments though to the master planned communities of today, which although certainly not peculiar to Queensland have become especially popular in the fast growing South East corner of the state. 


\section{Australian suburban life: the enduring promise and the experience}

A Davison has famously observed, Australia was born urban and quickly became suburban, embracing very soon in its colonial period a view of its settlement future comprising '..a sprawl of homes and gardens rather than a clumping of terraces and alleys' (Davison, 1999: 26). He notes also that despite an array of criticisms, the detached house and garden does bring with it some real, practical and enduring advantages. It is an adaptable form, and while the current tendency is to cover as much of the lot as possible with as large a dwelling as the local planning scheme allows, in the past suburban houses were more affordable because they were relatively small when first built. This allowed them to be extended as family size dictated and family budget allowed, and even provided the prospect of a minor subdivision of the land and the construction of one or mode additional dwellings at considerable profit. The surrounding garden has always provided the opportunity to grow food for the family, space for the children to play safely and a degree of visual and acoustic insulation from one's neighbours.

Davison claims that 'the detached house remains the goal of most young Australians' (p31) and that although the suburban dream has been 'quietly cut down to size' and lost some of its symbolism, 'its attractions remain strong'. But how do Davison's claims compare with recent evidence of housing preferences among Australians? In 2011 the Grattan Institute published the results of survey of 700 residents of Sydney and Melbourne in which they were asked a range of questions about their housing and locational preferences (Weidmann \& Kelly, 2011). In broad terms their results confirm many of the main elements of Davison's suburban dream, that the size of the house as measured by bedrooms and living spaces is of paramount importance, but so too are locational features such as being near to friends and family, the perceived safety of the area and the proximity of shops and public transport. Their data do not especially confirm the view that most people will 'drive till they qualify', in other words that they will be prepared to move further and further from urban centres until they are able to afford a detached house of certain size. But their most relevant findings show the need to segment the population as a whole when trying to understand housing preferences and recognise that household life stage serves as an important differentiating factor, along with ability and willingness to pay for different 
types of dwelling. Nevertheless, apartments remain for many of these population segments a dwelling type of last resort and something that most will be looking to move out from rather than into (Morrison and McMurray, 1999; Weidmann et al, 2011).

These empirical conclusions are echoed in many 'state of the market' reports prepared by research and consultancy bodies within the development industry (eg Wilson, 2015; NAB, 2015, UDIA, 2015). The Grattan Institute studies reveal an enduring overall preference for detached houses near to the centre of cities, even if most people (and especially younger households) recognise that this type of property and location is becoming increasingly unaffordable and that to be able to afford to buy a detached dwelling they will have to look to the fringes of the city. Although based on survey data collected from only a sample of Sydney and Melbourne residents, the Grattan studies suggest that at a more granular level, there is significant unmet demand for semi-detached houses across the city and for apartments in the outer areas. When different household types are taken into account, then we can see a more pronounced generational effect, whereby younger families with children appear more likely to value detachment over other factors including location, even though proximity to family and friends remains an important consideration. The size of the dwelling is also important with most households, including those within the younger age groups, looking to buy the largest detached house they can afford.

But what of the experience of those living in these newly built residential suburbs on the fringes of cities? While there are many accounts of life in suburban Australia, the ubiquity of both the built form and the lifestyle tend to make contrasts with a more distinctively urban form and lifestyle difficult. Nevertheless, recent research on the experience of living in newly-built, master-planned communities in South East Queensland (Cheshire et al, 2013; Rosenblatt et al, 2009) and national reviews of housing policy and expectations conducted by the Grattan Institute (Weidmann et al, 2011; Kelly et al, 2011; Kelly et al, 2013) provide useful insights on the changing experience of suburban life.

Cheshire and colleagues from the University of Queensland (UQ) have studied residents of a large master-planned community, developed by Delfin Lend Lease (now simply Lend Lease) at Springfield 
Lakes, some 20kms south-west of Brisbane in South East Queensland. When completed in 2020, Springfield Lakes is designed to accommodate 30,000 people, virtually all (93\%) in detached houses occupied by families rather than lone person households. In 2006 around two thirds of the completed dwellings were owner-occupied while one third were rented, although a number of these were occupied by prospective purchasers waiting for their houses to be constructed. The UQ survey and follow-up interviews were designed to investigate the ways in which residents of Springfield Lakes experienced community life and the extent to which this particular attempt to build an archetypal suburban community had succeeded. The research focussed on a number of characteristics thought to be significant in building 'community spirit', including knowing one’s neighbours and finding common interests with them, identifying with the place and feeling safe and secure when in it.

The data suggests that at that time Springfield Lakes had succeeded in becoming somewhere that residents felt was a 'good place to live' and in which they felt at home. A high proportion also believed that other residents 'shared their values', could be trusted and 'wanted the same things' from the place as they did: all hallmarks of the traditional suburban template. However, in terms of actual interaction with other residents, the data pointed to a different reality. While almost half (49\%) recognised people in their area, the same proportion stated that very few of their neighbours knew them; $44 \%$ said they never socialized with their neighbours and only $1 \%$ said they would turn to their neighbours in time of need. It would seem, therefore, that despite feeling at home, safe and secure in Springfield Lakes, many residents did not lead especially social lives in that place or conform to the stereotypical suburban existence of engaging regularly with their good neighbours who might be expected to go on to become good friends. These finding could, of course, be a reflection primarily of the newness of Springfield Lakes and that fact that the development of community spirit takes time, even when facilitated by a developer keen to present itself having a social conscience. The authors go on to echo earlier advice from Bryson and Winter (1999:174), based on their own research in an Australian new town of the 1960s, '..ban the motor car; make sure people work and play close to home and that they live in the same suburb all their lives'. However, this advice has not been heeded and the reality of most suburban 
residential developments in Australia over the last forty years is that they are places where car ownership is essential, there is an increasing separation of home and work and residential turnover is high.

In later work Cheshire and colleagues (2013) studied a broader sample of residential suburbs across the wider Brisbane region in order to compare more rigorously the characteristics and attitudes of the residents of master planned estates with those of other suburban types. Part of their analysis involved conducting a cluster analysis which generated five broad suburban types, each reflecting a different mix of age of residents, dominant household type, ethnicity of residents, density and social disadvantage. This cluster analysis also offers a useful foundation for exploring a more sophisticated typology of Australian suburbs, in particular whether these types signify other variations in suburban lifestyle.

\begin{tabular}{|l|l|}
\hline Cluster 1 & Average, young families \\
\hline Cluster 2 & Young, densely populated \\
\hline Cluster 3 & English speaking, advantaged, low density \\
\hline Cluster 4 & Disadvantaged and ethnically diverse \\
\hline Cluster 5 & Older, English speaking, disadvantaged \\
\hline
\end{tabular}

These suburban types in fact show relatively high degrees of similarity in terms of social cohesion, patterns of neighbouring and neighbourliness, and sense of social order. This is not to say that differences do not exist, but that they are not as pronounced as we might have expected. Furthermore, they suggest that some of the traditional assumptions of suburban sociability are not as strong as we might have assumed. Their results do however point to the importance of longevity in building community spirit: places designed to foster community spirit and sold on the basis of that promise do not and cannot deliver immediately on that promise. Of course this is an unremarkable conclusion; we have known for some time that community cannot be constructed as quickly as houses and that while some places may never develop a palpable sense of community, for most it simply takes decades rather than years to achieve and may even decline at certain points (Jacobs et al, 2011)

\section{The Australian template frays?}


The suburban template as a particular type of place in which to live a middle class life has, in Australia, become so commonplace that its descriptive integrity and explanatory value is now questionable. This fraying of the Australian suburban template has been a long and slow process, demonstrating the persistence of both the idea and the ideal in the face of a growing empirical challenge. This is evident on at least four dimensions: the economic; the social and political; the environmental and the cultural.

While there is a long standing political economy critique of urban forms and processes that focuses typically on whose interests are best served by development in general (eg Harvey, 1981) and by suburban development in particular (eg Walker, 1981), in this case we are concerned more with the idea that suburbs represent an economically rational place to live insofar as they provide reasonable access to jobs, social and community services and a pleasant peri-urban setting. While there is evidence in Australia and elsewhere of the increasing significance of polycentric metropolitan areas or 'cities of villages' (Lang and LeFurgy, 2003), there is also a growing awareness that in their early years at least, many of the new peri-urban suburbs are little more than dormitory settlements with few social and community facilities and insufficient local employment prospects to avoid the need for substantial commuting, usually by private car rather than public transport. The VAMPIRE indexes produced by Dodson and Sipe (2008) demonstrate the vulnerability of households with mortgages at the limit of affordability who also have a high exposure to fuel prices because of their car dependency and show how in most of the Australian capital cities, the areas with the highest proportions of vulnerable households are in the outer suburban areas. While the initial purchase price of property in these areas might be comparatively low, the VAMPIRE index reveals the longer term costs and vulnerabilities associated with living in these peri-urban locations and shows how the economic rationality of this type of suburban living is increasingly flawed.

The social critique of suburban living rests on the claim either that suburbs have never been places especially characterised by a strong sense of community spirit or neighbourliness or that in this respect they have in recent decades become indistinguishable from other urban neighbourhoods. A growing body of research in North America reveals the social, ethnic and class heterogeneity of suburban 
America (eg Lucy and Phillips, 2000; Hanlon, Short and Vicino, 2010; Kneebone and Berube, 2013) and some of the traditional assumptions of shared values, political attitudes and behaviour no longer hold (if they ever did). Recent work by Forrest and Hirayama (2015) extends this analysis beyond North America and shows how the post-war social project of homeownership in Europe (and probably in Australia) was seen as a 'bulwark against Bolshevism' or a path towards a politically stable property owning democracy. But empirical studies of the voting behaviour and political attitudes of suburban residents tend to present a more equivocal picture (eg Walks, 2013).

In recent years there has emerged a critique of the suburban built form that points to its association with an increasingly unsustainable consumptive lifestyle (Gleeson, 2010). This is partly a spatial argument based on the separation of home from work and the need to commute, typically in a private motor vehicle for all or at least part of the journey, and indeed of the need to drive to access most services such as shops, schools, parks and health centres. But it relates also to a so-called aspirational lifestyle that measures success in terms of goods purchased, including a detached house that now typically covers a higher proportion of the lot than previously (Hall, 2010) as well as cars, boats and a plethora of electronic appliances. While some argue that the lifestyle of most Australians is becoming ever more consumptive (Gleeson, 2010), there is a parallel argument about the comparative consumption profile of urban and suburban dwellers (those living in rural areas are rarely included in these calculations), with some suggesting that suburbia embodies and provokes over-consumption (eg Kunstler, 2005) while others present evidence of the comparatively higher energy consumption profiles of inner city apartment dwellers (eg Randolph and Troy, 2007). Whether these differences are related to spatial location, to lifestyle habits or to wealth remains the subject of considerable dispute, but there has been a clear (although contested) line of argument for some time that living in suburbia is inherently unsustainable through a combination of locational and lifestyle factors.

Because of its long standing association with middle classness and hence with notions of respectability and conformity, suburban culture has long been the object of scholarly attention, critique and analysis. In his infamous critique of 'Australian ugliness' Boyd (2010: 22) for example speaks of '..the street in 
the competitive suburb where every house feels obliged to suggest a high degree of success - or if not success then certainly superior taste.', while Greig (2004) categorises this as part of tendency among 'the Australian intelligensia' (sic) to denigrate the suburbs (or perhaps more pertinently suburban dwellers) for their 'materialism, anti-intellectualism, banality, false consciousness, marginalisation of women and cultural disinterest'. While this dichotomous view of suburbs as either the root of all goodness or of banality continues to serve as a convenient point of provocation in newspapers, blogs and even scholarly journals, it is perhaps best recognised as such and not treated as an unequivocal expression of empirical reality (Burton, 2011)

\section{Manifestations of fraying in South East Queensland}

If the contemporary suburban dream is to be found anywhere in Australia, it is surely in the masterplanned developments found usually on the fringes of our towns and cities. In their promotional material at least, these places continue to sell the long standing and archetypal suburban package of detached owner occupation, in places designed to combine housing with some local facilities and amenities, with equal access to urban services and rural landscapes. A brief survey of such development projects around the City of Gold Coast in South East Queensland suggests this ideological package does indeed continue to figure prominently in the promotional material provided by the developers, as the following brief selection shows.

Stockland is Australia's largest property group and a major developer of residential communities and at Ormeau Ridge in the northern part of the City Of Gold Coast is one of their flagship projects in the region. Their website emphasises both its rural location and the ability to live outdoors in stating that,

If space is important to you, Ormeau Ridge is a great place to come home to. The natural surroundings and outdoor lifestyle means you'll never want to leave, simply because it feels like home as you soon as you set foot inside the community.

But of course residents will have to leave every day to go to work, to school, to shop and for any out of home entertainment. Nevertheless, despite a pronounced lack of footpaths, it also claims that, 
House and land packages and a variety of blocks of land are for sale, offering a bealthy and active lifestyle. (emphasis added)

But in addition to these traditional suburban developments new housing products are now also being offered in these traditional peri-urban locations. Stockland itself is offering new small-lot products designed to be within the price reach of younger, first time buyers as well as retirees and empty nesters looking to downsize and mature age singles. In 2012 these house and land packages (a common form of new house sales in Australia where land is purchased and then a builder engaged to construct the dwelling) were offered at just under $\$ 300,000$ for freehold title with no body corporate fees for the maintenance of common property and facilities. They have also developed two bedroom/two bathroom, single storey houses of $104 \mathrm{~m}^{2}$ on $212 \mathrm{~m}^{2}$ lots selling (in 2013) for $\$ 270,000$ and twobedroom terrace or row housing of $93 \mathrm{~m}^{2}$ on $170 \mathrm{~m}^{2}$ lots. The motivation behind these offerings is simple: a significant section of the first time buyer market cannot afford anything else and Stockland would be missing a sales opportunity if it was not able to provide housing for this segment. The widely recognised ways of making houses more affordable and hence accessible to this segment of the market is through a combination of reducing lots sizes and house sizes, the use of cheaper materials and new, more efficient construction methods and, possibly and perhaps contentiously, through new funding methods. The Treasurer of the Australian Government called recently for a 'national conversation' about the merits of allowing (younger) first time buyers to access their Superannuation funds to help enter the housing market (Hockey, 2015).

On the western fringes of the City of Gold Coast, just beyond one of Stockland's major residential developments at Riverstone Crossing is another new residential subdivision located in former bushland. TJ International's Stone Creek (http://www.stonecreek.com.au/index.php) is described as a $\$ 70$ million boutique residential development that appeals especially to owner occupiers including 'Families and young couples [who] find the estate particularly appealing due to its high standard of landscaping and high quality house design', and the fact that, 
The estate features 51 hectares of pristine bushland in addition to the abundance of naturally formed creeks and lush eco-reserves that surround the estate. This in turn provides privacy for the residents with peaceful surrounds and no drive through traffic.

Recently released 'premium expansive' lots, which range from $500-600 \mathrm{~m}^{2}$ (or approximately half of the traditional suburban quarter acre block) have seen 'overwhelming demand' especially from those new to the region who are looking for 'a rural lifestyle with city conveniences at hand'.

Finally, between the Gold Coast and Brisbane, Lend Lease is planning a major new town at Yarrabilba. Initially a housing affordability project of the Queensland government's Urban Land Development Authority (ULDA), it now falls under the planning jurisdiction of Logan City Council while retaining its status as a Priority Development Area. It is expected to house 50,000 people in 20,000 dwellings (mostly detached) when completed in approximately 2050 and in its promotional literature, Lend Lease (2015) paints a classic picture of suburban bliss,

Balanced and beautiful, the vision for Yarrabilba is built on bringing you a complete community that nurtures traditional family values - providing you with a true sense of belonging.

The plans for the first neighbourhood include new shops, schools, an amazing super park, hike and bike trails, a sports oval and business centre - all just walking distance from your new front door.

Yarrabilba is proposed to be a convenient place to shop, with retail and commercial outlets located throughout the community. From the weekly supermarket round, to speciality shops, Yarrabilba will have it all. And as Yarrabilba grows, so will a vibrant Town Centre and Business Park. There will be thousands of jobs created through the retail, commercial, Town Centre and Business Park that will offer residents a better work / life balance so you can spend more time doing what you like instead of commuting to work.

And when it comes to education, apart from the many surrounding schools and child care facilities, Yarrabilba plans to offer 11 schools and many more child care centres, with the first to be provided in the first neighbourhood. 
At present though it is purely a residential estate and it is not clear when any of the community facilities, shops and work spaces will be built and its first pioneering residents will be able to enjoy this self-contained suburban lifestyle. For the time being, residents have to drive at least five kilometres to the nearest shops and forty kilometres to the employment opportunities of Brisbane.

Although mostly detached dwellings, there are already some examples of small lot housing at Yarrabilba, including row houses (terraced houses) which contribute to its presentation and perception as an area of relatively affordable housing, at least in terms of initial purchase price. Thus, resistance to these new small lot products comes not from the market - they sell quickly and easily - but from planners and politicians in local government, fearful that small lot housing developments run the risk of becoming 'the slums of the future'. Indeed, as noted above, Yarrabilba was instigated by the ULDA as part of a State-driven housing affordability initiative and would probably not have been approved by the local planning authority. Whether it succeeds in attracting shops, schools and employers remains to be seen and the timing of these elements is likely to be crucial in maintaining the saleability of the residential component and the viability of the whole scheme.

In fact it is the development of these large residential developments built way beyond the current suburban fringe and hence far from jobs and services, that are likely to be more vulnerable to increases in mortgage rates and petrol prices which increase the total cost of living in these areas. Especially if bought by investors rather than owner occupiers, estates of large houses in relatively remote locations in Australia are more likely to experience the fate of the Irish 'ghost estates' than more dense, smaller lot developments closer to public transport and urban services (Kitchin et al, 2014).

As suburban residential areas become places where attached as well as detached houses are now being built; where because of investor purchasing there are now significant numbers of renters, and where mature singles as well as empty nester downsizers are living alongside young families, so key elements of the traditional suburban template have become less pronounced. This is not, of course, to say that these new developments are inherently detrimental, simply that the 'traditional model' of suburbia is 
becoming increasingly variegated, to the point where it ceases to be a distinctive settlement pattern, location or lifestyle.

\section{Conclusions}

Our appreciation of suburbia once seemed relatively settled; we knew where the suburbs were and what constituted a suburban lifestyle. But like many remembrances of things past our vivid recollections of particular details do not always add up to a reliable and consistent picture of what actually was. While the notion of the suburb has been a significant feature of the Australian post-colonial landscape for the last two hundred years, it has never in fact been especially settled or immutable. This is not, however, a peculiarly Australian trait as both the idea and the experience of suburbia in North America and the UK have changed markedly over the last century. As Amin claims in respect of cities as a whole,

'..[they] are hardly discernible entities with distinct identities. They have become an endless inhabited sprawl without clear boundaries' (Amin, 2006).

while a recent study of Canadian metropolitan areas by Moos and Mendez (2014) found that although there is a positive relationship between higher incomes and suburban ways of living, these suburban spaces are becoming more diverse. As Florida (2014) observes, 'Not only are cities are looking more like suburbs, suburbs are looking more like cities.'

The idea of suburbia has always involved processes of idealisation and imagination, like Williams' idea of country and city. Indeed it has always relied on these opposites to enable the imagination of an ideal in-between space that embodies the best of both worlds. But these imagined cities and countrysides are just as likely to exist as much in the mind's eye as in empirical reality and so for the in-between spaces of suburbia.

A number of important questions remain about the future of suburbia in Australia: 
- Will pockets of traditionally conceived suburbia continue to spread even further outwards, driven by the availability of relatively cheap land and allowed by planning regimes that are either sympathetic or opposed to them but unable to resist?

- Will the long term running costs of housing (based on a combination of the design of the dwelling itself plus its location and access to services) become more important than the initial purchase price in the minds of prospective purchasers, ie will new conceptions of housing affordability take hold?

- Will the use value of home re-exert its hold on our understanding and appreciation of housing compared to the exchange value of property?

- Will we develop a better understanding of house prices, land prices and housing markets, such that the simple (but so far politically effective) call to release more land on the fringes of our cities in order to deliver affordable housing is widely seen also as simplistic?

But perhaps the most pressing question is whether the positive attributes of the suburban good life (and there will of course be profound disagreement over which attributes are positive and which are not) can be realised in other settings and places? If the desire to live as part of a community in which members feel safe, secure and able to call on their neighbours for help is in fact commonplace, can it not also be achieved in well-designed and constructed places located closer to centres of employment and service concentration and where medium or high density apartment blocks are the norm? Forrest et al's (2002) study of neighbourhood experiences in the high density, high rise city of Hong Kong suggests that some of these attributes (sense of belonging, contact with neighbours, valuing of local facilities such as parks) vary according to the socio-demographic characteristics of the residents as much as they do with built form and spatial location and in this respect justify some optimism about living a good life in places other than low density suburbs. 
For the last 227 years Australia has been profoundly influenced by British cultural norms, social values and political practices. But this influence has, for almost as long, been tempered by the norms, values and practices of other migrants and it is possible that contemporary Australia is now much more cosmopolitan and becoming more comfortable with the reality of being a country of the Asia-Pacific region as much as a former British colony. Perhaps this new cosmopolitanism will also drive a growing acceptance of new conceptions of how and where the 'good life' is best lived in Australia and $19^{\text {th }}$ and $20^{\text {th }}$ century British notions of suburbia as the answer to these questions will also slowly fade away.

There are signs that archetypal new suburban developments of free-standing residential dormitories are becoming increasingly rare and in the future they may remain only as somewhat anachronistic places, catering for a minority of suburban die-hards, committed to living in places that reflect their recollections of a past good life. For the rest of us, the increasing diversity of the Australian city life may well render the suburban good life template superfluous and see the term 'suburb' continue to denote little more than a named neighbourhood rather than a distinctive place or a way of life. 


\section{References}

Amin, A. (2006) The Good City, Urban Studies, vol 43, nos 5/6, 1009-1023

Barker, P. (2009) The Freedoms of Suburbia, London: Frances Lincoln Publishers

Boyd, R. (2010ed) The Australian Ugliness, Melbourne: The Text Publishing Company

Bryson, L., \& Winter, I. C. (1999) Social change, suburban lives: an Australian Newtown, 1960s to 1990s. Sydney: Allen \& Unwin.

Burton, P. (2011) 'On the outer' (Letter to Editor), The Australian Literary Review, 5 October 2011, p23

Cheshire, L., Wickes, R. and White, G. (2013) New Suburbs in the Making? Locating master planned estates in a comparative analysis of suburbs in South East Queensland, Urban Policy and Research, vol 31, no 3, 281-299

Davies, A. (2012) Is suburban living a neurotic condition? Crikey online, 19 August 2012

Davison, G. (2013) The Suburban Idea and its Enemies, Journal of Urban History, vol 39, no 5, 829847

Davison, G. (1999) Suburban character, People and Place, Vol. 7, No. 4, 26-31. Accessed on 19/4/15 at: $\leq$ http://search.informit.com.au/documentSummary; $\mathrm{dn}=200006021 ;$ res=IELAPA $>$

Dodson, J. and Sipe, N. (2008) Unsettling Suburbia: The New Landscape of Oil and Mortgage Vulnerability in Australian Cities, Urban Research Program Research Paper No. 17, Brisbane: Griffith University

Fishman, R. (1987) Bourgeois Utopias: The Rise and Fall of Suburbia, New York, NY: Basic Books

Florida, R. (2014) The fading distinction between city and suburb, The Atlantic: CityLab, retrieved http://www.citylab.com/politics/2014/10/the-fading-distinction-between-city-and-suburb/381096/ $(13 / 4 / 2015)$

Forrest, R and Hirayama, Y. (2015) The financialisation of the social project: Embedded liberalism, neoliberalism and home ownership, Urban Studies, vol 52, no 2, 233-244

Forrest, R., La Grange, A. and Ngai-Ming, Y. (2002) Neighbourhood in a high rise, high density city: some observations on contemporary Hong Kong, The Sociological Review, vol 50, no 2, 215-240

Fox, A. (2014) Why suburbia snobs are wrong, The Guardian online edition, 14 January 2014

Freestone, R. (2010) Urban Nation: Australia's planning heritage, Collingwood, VIC: CSIRO Publishing

Giddens, A. (1984) The Constitution of Society: Outline of the theory of structuration, Cambridge: Polity Press 
Gleeson, B. (2010) Lifeboat Cities, Sydney: UNSW Press

Grieg, A. (2004) The way we live, Griffith Review, no 2,

Hall, P. (1974) The Containment of Urban England, The Geographical Journal, vol 140, no 3, 386-408

Hall, T. (2010) The life and death of the Australian backyard, Collingwood, VIC: CSIRO Publishing

Hanlon, B., Short, J, and Vicino, T. (2010) Cities and suburbs: New metropolitan realities in the US, New York: Routledge

Harvey, D. (1981) 'The urban process under capitalism: a framework for analysis' in M Dear and A Scott (eds) Urbanization and urban planning in capitalist society, London: Methuen, 91-121

Harvey, D. (1989).The urban experience, Baltimore: Johns Hopkins University Press.

Healy, C. (ed) (1994) The Beasts of Suburbia: reinterpreting cultures in Australian suburbs, Melbourne: MUP

Hockey, J. (2015) 'Transcript of interview with David Koch, Sunrise, Cannel 7', 6 March, accessed on 19/4/15 at: http://jbh.ministers.treasury.gov.au/transcript/043-2015/

Jacobs, K and Arthurson, K and Cica, N and Greenwood, A and Hastings, A, (2011) The stigmatisation of social housing: findings from a panel investigation, AHURI Final Report Series, no $166,1-34$.

Kelly, J-F. Weidmann, B. and Walsh, M. (2011) The Housing We'd Choose, Melbourne: Grattan Institute

King, S. (2013) Stop demonising McMansions, The Conversation, 19 November 2013

Kitchin, R., O'Callaghan, C. and Gleeson, J. (2014) The New Ruins of Ireland? Unfinished estates in the Post-Celtic Tiger Era, International Journal of Urban and Regional Research, vol 38, no 3, 10691080

Kneebone, E. and Berube, A. (2013) Confronting suburban poverty in America, Washington, DC: The Brookings Institution

Kunstler, J.H. (2005) The Long Emergency: surviving the end of oil, climate change, and other converging catastrophes of the twenty first century, New York: Grove Press

Lang, R. and LeFurgy, J. (2003) Edgeless Cities: Examining the noncentred metropolis, Housing Policy Debate, vol 14, no 3, 427-460

Lang, R. and LeFurgy, J. (2007) Boomburgs,: The Rise of America's Accidental Cities, Washington, DC: Brookings Institution Press

Lend Lease (2015) Yarrabilba: Community Vision, available at: http://www.yarrabilba.com.au/Community-Vision 
Lucy, W. and Phillips, D. (2000) Confronting suburban decline: strategic planning for metropolitan renewal, Washington: Island Press

Mechlenborg, M. (2007) 'The concept of suburbia and modernity', paper presented to ENHR Conference, Sustainable Urban Areas, Rottererdam, 25-28 June,

Moos, M. and Mendez, P. (2014) Suburban ways of living and the geography of income: How homeownership, single family dwellings and automobile use define the metropolitan social space. Urban Studies, DOI: 10.1177/0042098014538679

Morgan, K. (2012) Australia: a very short introduction, Oxford: OUP

Morrison, P. and McMurray, S. (1999) The Inner-city apartment versus the Suburb: Housing Submarkets in a New Zealand City, Urban Studies, vol 36, no 2, 377-397

NAB (2015) Australian Housing Market Report, National Australia Bank

Pini, B. \& Previte, J. (2013) Bourdieu, the boom and cashed-up Bogans, Journal of Sociology, vol 49, nos 2-3, 256-271

Randolph, B. and Troy, P. (2007) Energy Consumption and the Built Environment: A social and behavioural analysis, Research Paper No 7, City Futures Research Centre, Sydney: University of New South Wales

Rosenblatt, T., Cheshire, L. and Lawrence, G. (2009) Social Interaction and Sense of Community in a Master Planned Community, Housing, Theory and Society, vol 26, no 2, 122-142

Sieverts, T. (2003) Cities without cities: an interpretation of the Zwischenstadt, London, Spon Press

Stretton, H. (1971) Ideas for Australian Cities, Melbourne: Georgian House

Troy, P. (1996) The Perils of Urban Consolidation, Sydney: Federation Press

UDIA (2015) The UDIA Queensland State of the Market Report, Brisbane: Urban Development Institute of Australia (Qld) Research Foundation

Walker, R. (1981) 'A theory of suburbanisation: capitalism and the construction of urban space in the United States', in M Dear and A Scott (eds) Urbanization and urban planning in capitalist society, London: Methuen, 383-429

Walks, A. (2013) Suburbanism as a way of life, slight return, Urban Studies, vol 50, no 8, 1471-1488

Weidmann B. and Kelly, J-F. (2011) What Matters Most? Housing preferences across the population, Melbourne: Grattan Institute

Williams, R. (1973) The Country and the City, London: Chatto and Windus

Wilson, A. (2015) State of the Market Report, Domain Group 
Winton, T. (2013) Some thoughts about class in Australia: The C word, The Monthly, December/January accessed on 19/4/2015 at:

https://www.themonthly.com.au/issue/2013/december/1385816400/tim-winton/c-word 